\title{
Lithospheric cooling trends and deviations in oceanic PP-P and $S S-S$ differential traveltimes
}

\author{
Saskia Goes, ${ }^{1}$ Caroline M. Eakin, ${ }^{1,3}$ and Jeroen Ritsema ${ }^{2}$ \\ Received 31 July 2012; revised 17 December 2012; accepted 14 January 2013; published 4 March 2013.
}

[1] The thermal and compositional structure of oceanic lithosphere, which exerts an important control on plate behavior, is still debated. Our set of 60,000 PP-P and $S S-S$ traveltime differences with oceanic $P P$ and $S S$ bounce points provides a good constraint on both compressional- and shear-wave velocity. By calculating traveltimes for thermal models that are converted to seismic structures with a thermodynamic approach, we test whether lithospheric cooling can explain $P P-P$ and $S S-S$ traveltime variations with plate age. The $P P-P$ and $S S-S$ traveltimes have substantial scatter but, on average, decrease by 0.2 and $0.7 \mathrm{~s} / \mathrm{Myr}^{1 / 2}$, respectively, when the $P P$ and $S S$ waves reflect off progressively older oceanic crust. Both a half-space and a plate cooling model with a mid-ocean ridge basalt-source mantle potential temperature $\left(1315^{\circ} \pm 50^{\circ} \mathrm{C}\right)$ explain the average values of the $P P$ - $P$ and $S S-S$ anomalies and their decrease with plate age. Residual $P P-P$ and $S S-S$ anomalies relative to a cooling model reveal large-scale patterns. Along a few paths (e.g., Tonga-Fiji to western North America), seismic heterogeneity in the deep mantle is responsible for a significant fraction of the PP-P and $S S-S$ traveltime variation. Most anomalies probably correspond to broad temperature variations in the upper mantle, such as a very slow central-northern Pacific (which may require a $100^{\circ} \mathrm{C}$ excess temperature) and high- and low-velocity anomalies along the ridges that correlate with deep and shallow bathymetry, respectively.

Citation: Goes, S., C. M. Eakin, and J. Ritsema (2013), Lithospheric cooling trends and deviations in oceanic $P P$ - $P$ and SS-S differential traveltimes, J. Geophys. Res. Solid Earth, 118, 996-1007, doi:10.1002/jgrb.50092.

\section{Introduction}

[2] The formation and subduction of oceanic lithosphere are fundamental plate tectonic processes. Generally, the structure of oceanic lithosphere is considered to be simple and well understood. Bathymetry, heat flow, the geoid, and surface-wave imaging indicate that the thickness of the oceanic lithosphere grows as a function of the square root of its age, as expected for conductive cooling. Nevertheless, it is still debated whether a pure half-space cooling model or models with additional heat input at the plate's base (such as the plate model) are more appropriate descriptions [e.g., Korenaga and Korenaga, 2008; Maggi et al., 2006; Nishimura and Forsyth, 1989; Parson and Sclater, 1977; Ritzwoller et al., 2004; Smith and Sandwell, 1997]. Several studies have documented additional variability in the structure of the oceanic lithosphere-asthenosphere system, comprising anomalies

\footnotetext{
${ }^{1}$ Department of Earth Science and Engineering, Imperial College London, London, UK.

${ }^{2}$ Department of Earth and Environmental Sciences, University of Michigan, Ann Arbor, Michigan, USA.

${ }^{3}$ Department of Geology and Geophysics, Yale University, New Haven, Connecticut, USA.

Corresponding author: S. Goes, Department of Earth Science and Engineering, Imperial College London, London, UK SW7 2AZ. Tel: +4420-759 46434. (e-mail: s.goes@imperial.ac.uk)

(C)2013. American Geophysical Union. All Rights Reserved. 2169-9313/13/10.1002/jgrb.50092
}

in bulk velocities and the possibly widespread occurrence of a sharp seismic discontinuity near the expected depth of the lithosphere-asthenosphere transition (commonly termed "LAB" for lithosphere-asthenosphere boundary) [e.g., Buck et al., 2009; Harmon et al., 2011; Hillier and Watts, 2005; Kawakatsu et al., 2009; Rychert et al., 2012; Zlotnik et al., 2008]. Such variability has been attributed to plume activity, melting, and/or small-scale convective processes and would create age-independent variations in plate buoyancy and strength.

[3] Seismic studies of the bulk structure of oceanic lithosphere-asthenosphere are primarily based on the dispersion of surface waves. Although surface waves provide worldwide coverage of the oceanic lithosphere, surface-wave dispersion is only sensitive to the shear-wave speed (and attenuation) structure of the upper mantle [Maggi et al., 2006; Nishimura and Forsyth, 1989; Shapiro and Ritzwoller, 2004a]. In this study, we analyze the traveltimes of $P P$ and $S S$ waves. Albeit with relatively poor vertical resolution, $P P$ and $S S$ traveltimes complement the surface-wave dispersion data with constraints on broad structure in both shear- and compressional-wave speed.

[4] Previous studies have shown that $P P-P$ and $S S-S$ differential traveltimes are predominantly sensitive to large-scale variations of wave speed in the upper mantle [e.g., Bhattacharyya et al., 1996; Reid et al., 2001; Ritsema and Van Heijst, 2002; Ritsema et al., 2002; Woodward and Masters, 1991]. In particular, there is a clear ocean-continent signature in both $P P-P$ and SS-S. Woodward and Masters [1991] demonstrated that $P P-P$ and $S S-S$ traveltime anomalies for oceanic paths vary with plate age. We follow up on this study with a data set that 
is an order of magnitude larger than available in the early 1990s. We quantitatively compare the seismic data with predictions of traveltimes through the thermal structure of different cooling models of the oceanic lithosphere. The thermal structures are converted to seismic velocity using the most recent experimental constraints on the relationships between temperature and wave speed of the uppermost mantle. This allows us to assess to what extent oceanic differential traveltimes can be explained by lithospheric cooling.

\section{Differential Traveltime Data}

\subsection{Global Data Set}

[5] We use the expanded database of traveltime measurements originally compiled by Ritsema and Van Heijst [2002]. It contains approximately 500,000 PP-P and $S S-S$ differential traveltimes. It is based on measurements from more than 4000 earthquakes (1980-2008) of magnitude 5.9 and larger and all global and regional waveform data archived at the Incorporated Research Institutions for Seismology (IRIS) Data Management Center. Traveltime measurements are made by cross-correlating synthetic waveforms with low-pass filtered recordings $(T=16-200 \mathrm{~s}$, dominant periods of the waveforms are near the lower end of this range) [Ritsema and Van Heijst, 2002]. The traveltime contributions due to Earth's ellipticity and due to the heterogeneous crustal structure are removed following Ritsema et al. [2009]. We analyze the traveltime differences of $P P-P$ and $S S-S$ as anomalies with respect to IASP91 [Kennett and Engdahl, 1991]. Thus, an anomaly in $P P-P$ and $S S-S$ is the observed difference in the $P P$ and $P$ (or $S S$ and $S$ ) traveltime minus the differential traveltime predicted by IASP91. Anomalies with respect to the preliminary reference Earth model are similar, but the $220-\mathrm{km}$ discontinuity in this reference model complicates the comparison with physical models [Cammarano et al., 2003].

[6] The ray paths of the direct $(P$ or $S)$ and reflected ( $P P$ or $S S$ ) phases differ the most beneath the bounce point of the reflected wave (Figure 1). Therefore, $P P-P$ and $S S-S$ anomalies are not influenced by earthquake mislocations and near-source and near-receiver structure. Previous studies have shown that differential traveltimes predominantly reflect shallow mantle structure below the bounce points, because velocity anomalies are largest in the uppermost mantle. The lower mantle contribution is generally $<30 \%$ [Woodward and Masters, 1991]. Our analyses confirm the dominant upper-mantle signature; however, as discussed below, for

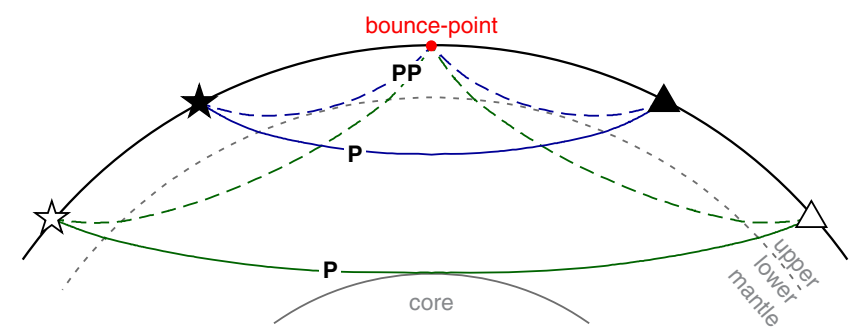

Figure 1. Comparison of the paths traveled by (solid lines) direct $(P$ or $S)$ and (dashed lines) reflected body (PP or $S S$ ) waves for a $58^{\circ}$ and $98^{\circ}$ long path (representative of the minimum and maximum distances considered in our oceanic analyses). The paths are almost identical near the source and receiver. a few source-receiver paths, we find that the lower mantle contribution is equally strong.

[7] Figure 2 shows the global distribution of $P P-P$ and $S S-S$ anomalies. Both $P P-P$ (Figure 2a) and $S S-S$ (Figure 2b) anomalies are positive over the oceans, indicating lowerthan-average wave speeds, and negative over continental regions, indicating higher-than-average velocities. The anomalies are most positive near mid-ocean ridges and most negative within the cratons. Note that the shapes of the anomalies are in part determined by data coverage. Compressional and shear differential traveltime anomalies have very similar patterns for the oceanic regions. However, the low-velocity region over the central and especially western Pacific appears more pronounced in the compressional anomalies, whereas the fast anomalies in the Philippine Sea are more dominant in the shear anomalies. The tectonic pattern confirms that $P P-P$ and $S S-S$ traveltimes are controlled primarily by wave-speed heterogeneity in the upper mantle.

\subsection{Oceanic Traveltimes}

[8] Figure 3 shows histograms of the $P P-P$ and $S S-S$ anomalies for oceanic and continental bounce points. The $S S-S$ traveltime anomalies are approximately two times larger than the $P P-P$ anomalies. This indicates that shearand compressional-wave velocity perturbations are equally strong, that is, $d \ln \mathrm{V}_{S} / \mathrm{dln}_{P}=1$, in the uppermost mantle. The mean of the continental $P P-P$ and $S S-S$ traveltime anomalies is about zero. For the oceanic bounce points, it is about $+2.8 \mathrm{~s}$ for $P P-P$ and $+3.5 \mathrm{~s}$ for $S S-S$, although the $S S-S$ distribution is more skewed than that of $P P-P$. These positive values are expected because the thermal lithosphere beneath oceans is thinner than beneath continents. However, if the traveltime delays have a purely thermal origin, one would expect $S S-S$ anomalies to be about twice as large as $P P-P$ because of the stronger sensitivity of $\mathrm{V}_{S}$ to temperature. Instead, the means are similar in magnitude.

[9] In our subsequent analyses, we consider the 60,000 highest-quality $P P-P$ and $S S-S$ anomalies associated with oceanic $P P$ and $S S$ bounce points that are recorded in the epicentral distance range $55^{\circ}-100^{\circ}$. Within this distance range, the influence of sharp gradients in the transition zone and $\mathrm{D}^{\prime \prime}$ region is not strong. $P, P P, S$, and $S S$ turn below the uppermantle transition zone and $P$ and $S$ waves do not diffract a long distance along the core (Figure 1). PP-P and $S S-S$ do not vary systematically as a function of epicentral distance (Figure 4). This is consistent with a dominant influence of upper-mantle structure and indicates that they are not affected by unmodeled 1-D structure. Figure 5 shows that the oceanic differential traveltimes correlate strongly with the traveltimes of the reflected phases, which sample the upper mantle below the bounce points. Again, this confirms that the differential traveltimes largely reflect upper-mantle structure.

\subsection{Traveltime-Age Trends}

[10] We assign lithospheric ages to $P P-P$ and $S S-S$ data at their bounce points using the $1^{\circ} \times 1^{\circ}$ age grid compiled by Müller et al. [2008]. The PP-P and $S S-S$ anomalies as a function of age have a scatter of \pm 3 and $\pm 6 \mathrm{~s}$, respectively (Figure 6). The large scatter indicates substantial age-independent heterogeneity beneath all oceans. Besides the uppermost mantle structure, crust and deep mantle heterogeneity may contribute to $P P-P$ and $S S-S$ (Figure 1). 

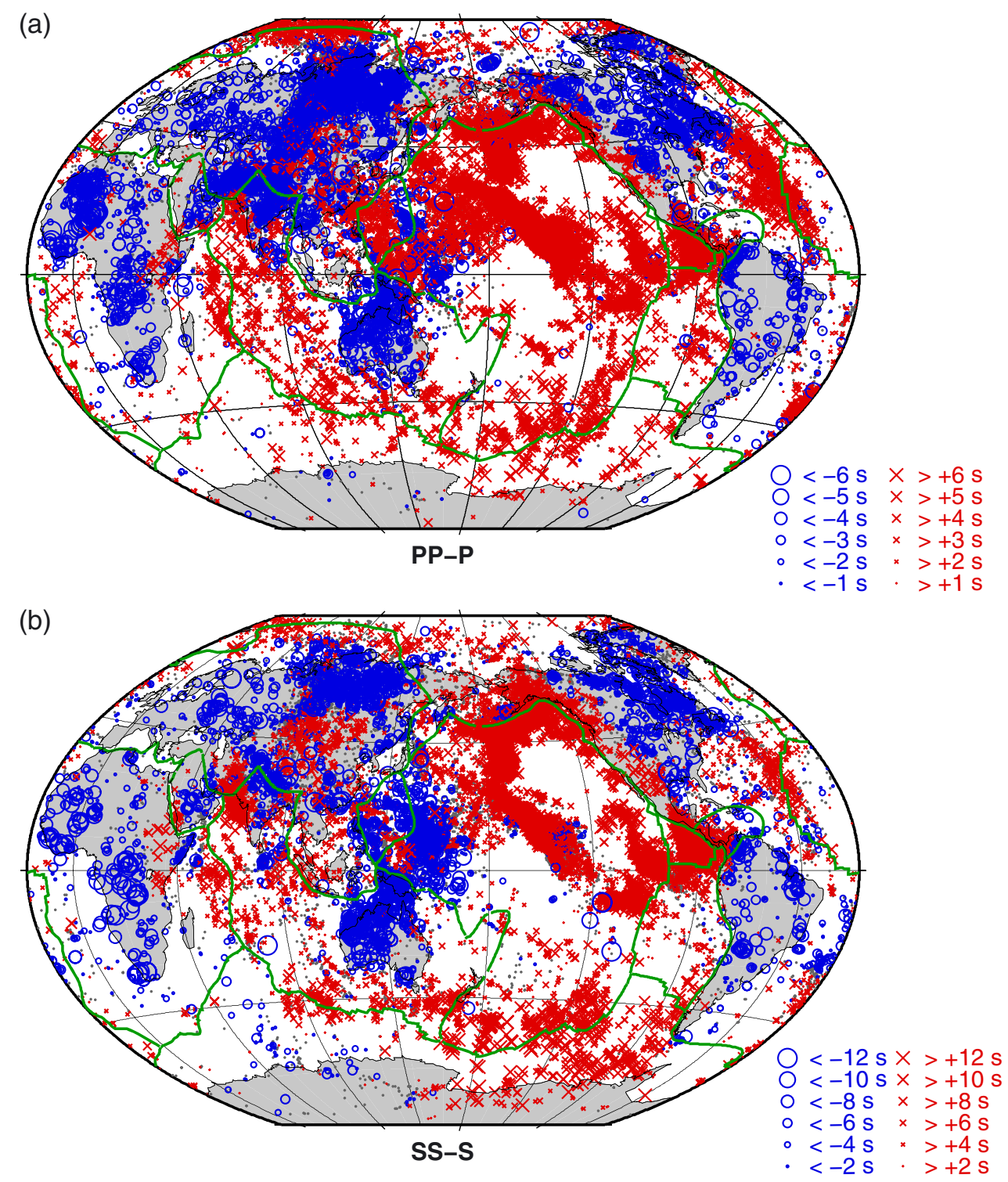

Figure 2. $\quad P P-P($ a) and $S S-S($ b) traveltime anomalies with respect to IASP91, corrected for crustal structure. The anomalies are plotted at the $P P$ and $S S$ bounce points. (red crosses) Positive (slow) anomalies. (blue circles) Negative (fast) anomalies.

[11] Nevertheless, it is clear (Figure 6) that PP-P and SS-S decrease with increasing lithospheric age. The age trend is more pronounced in $P P-P$ and $S S-S$, where near-source and near-receiver effects are absent, than in the $P P$ or $S S$ traveltime anomalies (Figures A1 and A2). $P$ and $S$ data display no age trend, so the trend in $P P-P$ and $S S-S$ is an upper-mantle signature. $P P-P$ and $S S-S$ with Pacific bounce points $(\sim 75 \%$ of the total data set) have, on average, larger positive residuals than the anomalies for the other oceans (Figure 6).

[12] Least-squares line fits to the square root of age trend of the mean values (for $4 \mathrm{Myr}$ age bins) through the $P P-P$ residuals are described by $(-0.20 \pm 0.0030) \cdot t^{1 / 2}+(4.3 \pm 0.28)$ $\mathrm{s}$ for the Pacific and $(-0.22 \pm 0.0023) \cdot t^{1 / 2}+(3.5 \pm 0.23) \mathrm{s}$ for the other oceans (Figure 6). Here, $t$ is the age of the oceanic crust in millions of years. For the $S S-S$ data, the best-fitting lines are $(-0.72 \pm 0.073) \cdot t^{1 / 2}+(9.4 \pm 0.68) \mathrm{s}$ for the Pacific bounce points and $(-0.68 \pm 0.089) \cdot t^{1 / 2}+(7.4 \pm 0.82) \mathrm{s}$ for the other oceans. Errors are estimated from the line misfit, assuming errors in each mean value are the same. Formal errors in the means, from the standard deviation of the distribution and number of data points, are likely too small as many age ranges are dominantly sampled by only a select set of paths. Nonetheless, similar slopes and y-intercepts (with smaller error estimates) are found if these standard deviations in the mean are used in linear-trend fitting. The correlation of means with $t^{1 / 2}$ is statistically significant at $\mathrm{R}$ values between 0.71 and 0.84 . The scatter of the means around the trends is evidence of additional non-age-dependent structure.

[13] For comparison, Woodward and Masters [1991] found slopes of $(-0.18 \pm 0.01)$ and $(-0.51 \pm 0.01) \mathrm{s} / \mathrm{Myr}^{1 / 2}$ for much smaller $P P-P$ and $S S-S$ data sets, respectively. They determined a similar $P$ traveltime trend, but their estimate of the $S S-S$ traveltime slope may be affected more strongly by dominant sampling of the slow central Pacific. The fact that we find similar slopes for all oceans and that the 

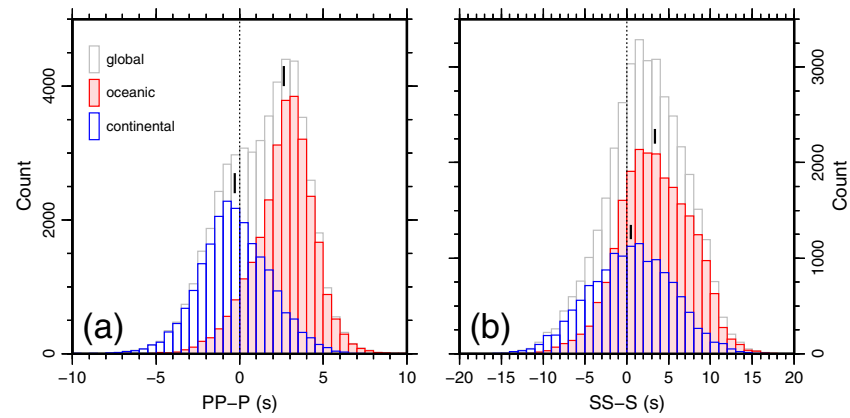

Figure 3. Histograms of the $P P-P$ and $S S-S$ differential traveltimes from Figure 2, as a global data set (gray), and separated into oceanic (red and shaded) and continental (blue and unfilled) bounce points. (bold black lines) Mean values for the oceanic and continental distributions. Anomalies are centered near zero for the continents but have a positive deviation of $\sim 3$ s for both $P$ and $S$ data in the oceans. Note that the timescale for $S S-S$ is double that of $P P-P$.

slopes and offsets are larger for $S$ than for $P$ residuals points to a first-order thermal signature of lithospheric cooling.

\section{Modeling Methods}

\subsection{Cooling Models}

\subsubsection{Thermal Structure}

[14] We consider two end-member models of conductive cooling of the lithosphere: (1) the half-space cooling model and (2) the plate model (Figure 7). Half-space cooling, in which the lithosphere continuously thickens as $t^{1 / 2}$, provides a maximum lithospheric thickness end-member. However, at ages larger than $70 \mathrm{Myr}$, bathymetry, surface heat flow, and the geoid indicate that the lithosphere is, on average, thinner than predicted from half-space cooling [e.g., Doin and Fleitout, 1996; Parson and Sclater, 1977]. There is considerable debate about the mechanism that limits lithospheric thickening. Small-scale convection, which thermally erodes the base of the plate, and an increased likelihood of reheating with plate age (e.g., by
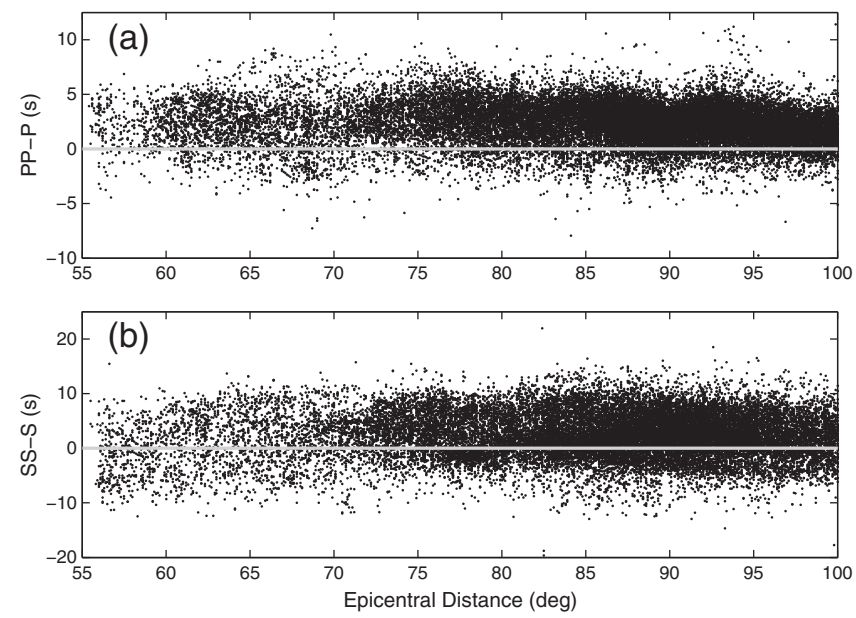

Figure 4. Differential (a) $P P-P$ and (b) $S S-S$ traveltimes (relative to IASP91) versus epicentral distance for all data with oceanic bounce points. The absence of a trend strengthens the interpretation that these traveltimes are influenced most strongly by shallow mantle structure.
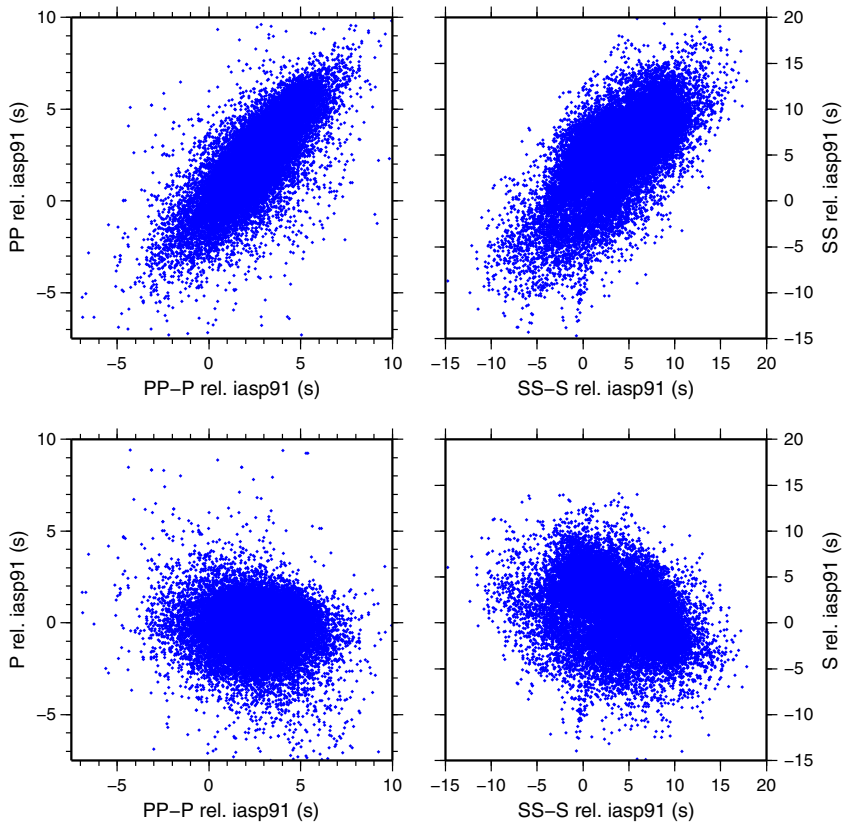

Figure 5. Correlation between differential $(P P-P$ or $S S-S)$ traveltimes with traveltimes of the reflected $(P P$ or $S S)$ and direct $(P$ or $S$ ) phases. The $P P$ and $S S$ have oceanic bounce points. Scales for $S$ traveltimes are twice those of $P$ traveltimes. Differential traveltimes correlate strongly with the traveltimes of the reflected phases.

plumes) have been proposed as possible causes [Davaille and Jaupart, 1994; Huang and Zhong, 2005; Korenaga and Korenaga, 2008; Parson and Sclater, 1977; Smith and Sandwell, 1997]. Rather than simulating a specific physical mechanism, the plate model imposes a limit on maximum thermal thickness [e.g., McKenzie et al., 2005; Stein and Stein, 1992], thus providing a minimum lithospheric thickness end-member.

[15] We numerically solve for the thermal structures of the plate and half-space models using the equations and parameters from McKenzie et al. [2005]. The mantle potential temperature is chosen to be $1315^{\circ} \mathrm{C}$, consistent with the temperatures estimated petrologically for a mid-ocean ridge basalt (MORB)-source mantle [Herzberg et al., 2007]. For temperature-dependent conductivity, we used model kH [after Hofmeister, 1999; McKenzie et al., 2005]. The plate thickness in the plate model is $103 \mathrm{~km}$, a value that provides a good fit to bathymetry and heat flow data. Below 103-km depth, we set the temperature profile to an adiabat with the same potential temperature. We calculate this adiabat for a pyrolitic composition with a full thermodynamic approach (see section 3.2). A constant adiabatic thermal gradient is added to the plate temperatures to link it smoothly to the mantle adiabat below. The half-space cooling model has the same thermal parameters, but plate thickness is set to $400 \mathrm{~km}$, a depth not reached by cooling for the 200-Myr history considered. An adiabatic gradient of $0.456 \mathrm{~K} / \mathrm{km}$ added to this structure yields a similar average adiabatic gradient as for the full thermodynamic calculation. Temperatures as a function of age for the two models are shown in Figure 7.

\subsubsection{Compositional Structure and Neglecting Melt}

[16] We chose a compositional structure that reflects the depletion effects of melting at the ridge. It is derived from a dynamic ridge-spreading model with the same potential 

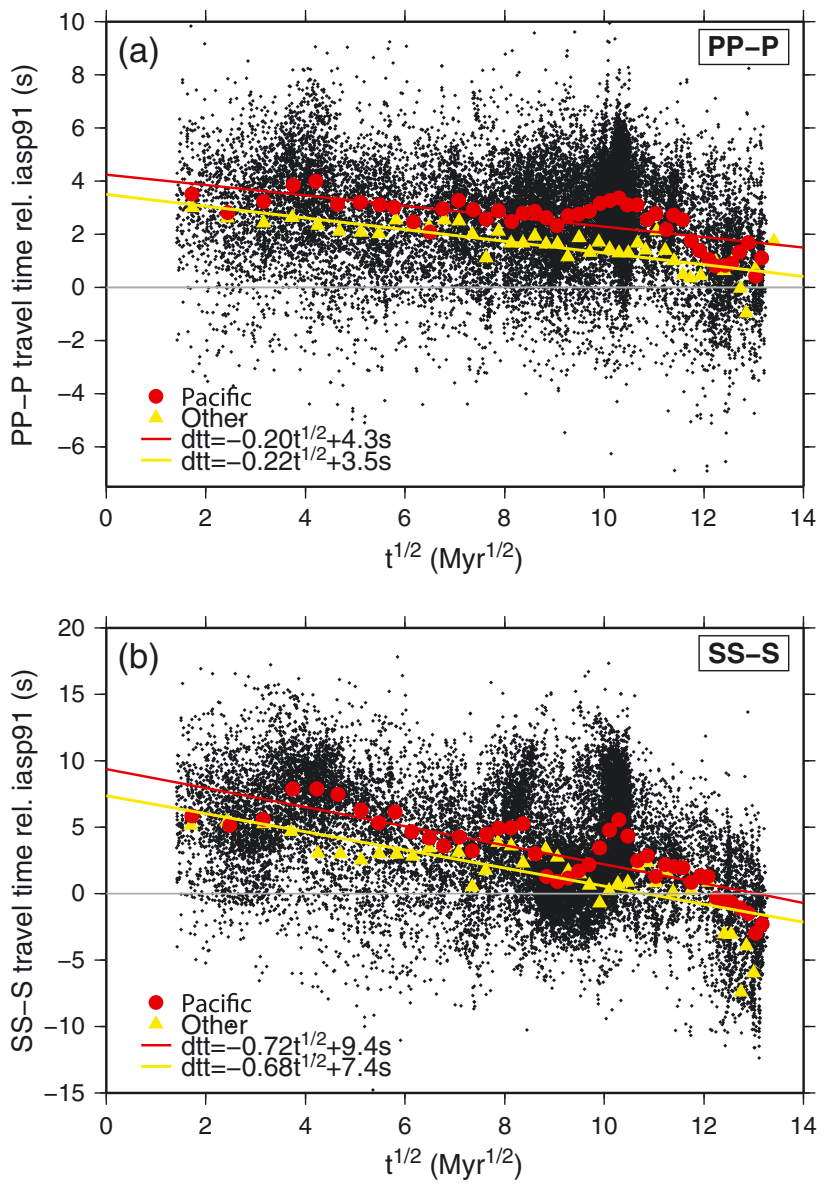

Figure 6. Differential $P P-P(a)$ and $S S-S(b)$ traveltimes as a function of the square root of plate age, $t^{1 / 2}$. (black dots) Full oceanic data set. (red symbols) Mean traveltimes for the Pacific data. (yellow symbols) Mean traveltimes for all other oceans. Lines are least-square fits to the means.

temperature as the cooling models [Goes et al., 2012]. This model includes melting relations and tracks major-element depletion, dehydration, and (1-D) melt migration. Based on these ridge models, major-element depletion in our cooling models is implemented as a linear change from a pyrolitic to a harzburgitic composition between 85 - and 19-km depth [compositions from $\mathrm{Xu}$ et al., 2008]. Water content, $\mathrm{C}_{\mathrm{OH}}$, decreases linearly from that appropriate for a damp MORBsource mantle $\left(C_{\mathrm{OH}}=1000 \mathrm{H} / 10^{6} \mathrm{Si}\right)$ [Hirth and Kohlstedt, $1996]$ to dry $\left(C_{\mathrm{OH}}=50 \mathrm{H} / 10^{6} \mathrm{Si}\right)$ from the start of hydrous melting at $85-\mathrm{km}$ depth to the onset of dry melting at 52-km depth.

[17] Our dynamic model showed that, even with melt mobility parameters at the low end of petrological constraints, and seismic sensitivity to melt at the high end of what has been found experimentally and theoretically, melt contents of the asthenosphere below lithosphere older than $\sim 1.5$ Myr have a negligible effect on the overall velocity structure [Goes et al., 2012]. Furthermore, we found that melt is not required to reconcile the predicted subridge structure or oceanic cooling models with constraints on oceanic shear wave speed and attenuation from a range of studies. A number of other studies have previously inferred a minor role of melt in large-scale asthenospheric seismic structure [Faul and Jackson,
2005; Karato, 2012; Shapiro and Ritzwoller, 2004b; Stixrude and Lithgow-Bertelloni, 2005]. The differential traveltimes we study here have insufficient vertical resolution to shed further light on the nature of the "LAB" discontinuity, which is sometimes associated with a melt layer [e.g., Kawakatsu et al., 2009]. For the reasons outlined, we focus on lithosphere of ages $>2 \mathrm{Myr}$ and neglect melt in the cooling models.

\subsection{Synthetic Seismic Velocities}

[18] Phase diagrams and anharmonic velocities are calculated using the code PerPleX [Connolly, 2005] and the equation of state, solid-solution models and 2008-NaCFMAS mineral parameter database from Stixrude and Lithgow-Bertelloni [2005] and Xu et al. [2008]. Major-element depletion affects the synthetic anharmonic velocities. The differences in seismic velocity for a pyrolitic and harzburgitic composition are small, except in the plagioclase stability field, which only covers a narrow depth region below the crust. Hence, the exact parameterization of the major-element composition between an undepleted peridotite and a melt-depleted harzburgite has little effect on the predicted seismic structure.

[19] Effects of water are only incorporated in anelasticity. At temperatures close to the mantle adiabat, anelasticity has a very strong effect on velocity [e.g., Jackson et al., 2002; Karato, 1993; Karato and Spetzler, 1990; McCarthy et al., 2011], giving rise to a low-velocity zone at asthenospheric depths. We use a shear-attenuation model denoted as " $Q_{F}$ " based on the experimental constraints from Faul and Jackson [2005] and Jackson et al. [2002] and the formulation and parameter values as proposed by Behn et al. [2009]. Behn et al. [2009] incorporated the effect of hydration and adapted the grain-size depth
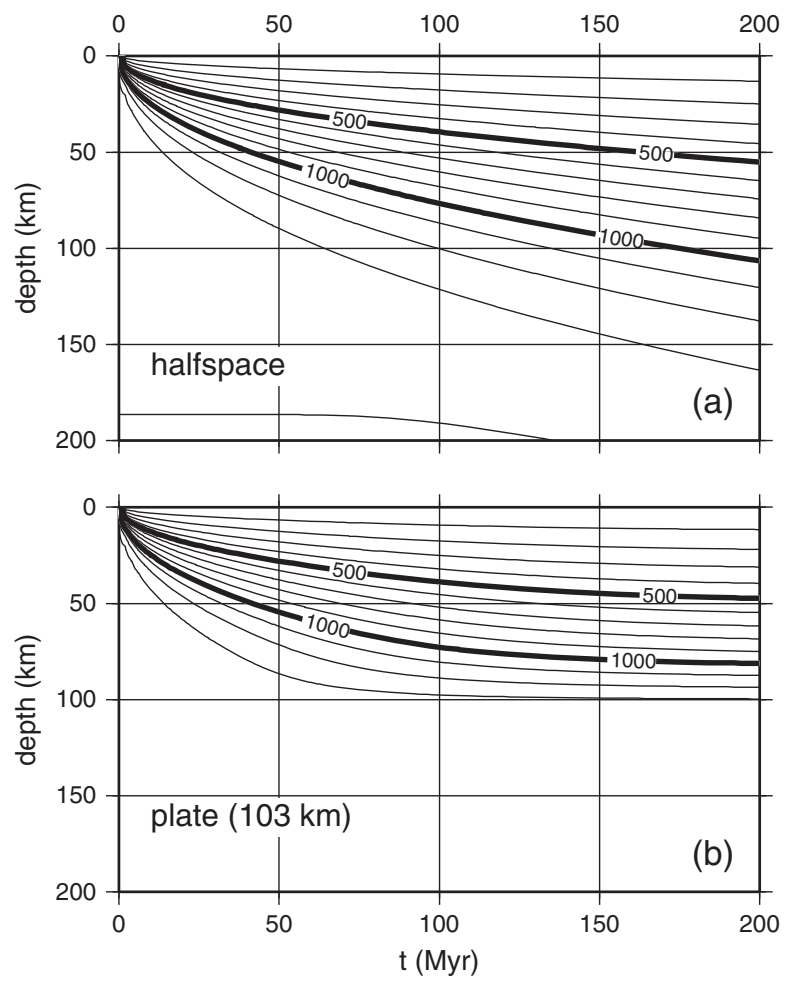

Figure 7. Thermal lithospheric cooling structures as a function of age: (a) half-space cooling, (b) 103-km-thick plate model with parameters from McKenzie et al. [2005]. Contours are drawn every $100^{\circ} \mathrm{C}$, with bold contours every $500^{\circ} \mathrm{C}$. 

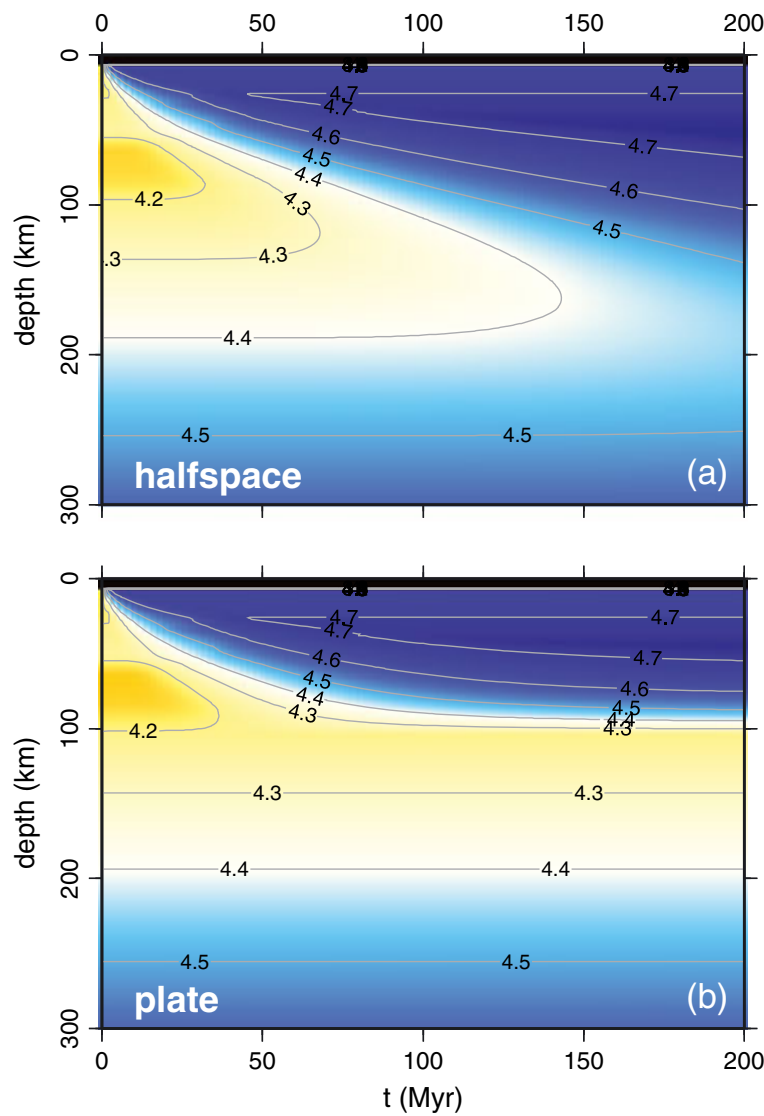

Figure 8. Shear-wave velocity structure for the half-space (a) and plate cooling (b) models from Figure 7. Note that this figure spans 1.5 times the depth scale shown in Figure 7. The calculations take into account the effects of major-element depletion and dehydration using anelasticity model $\mathrm{Q}_{\mathrm{F}}$ [Behn et al., 2009; Faul and Jackson, 2005]. The plate model predicts a narrow and constant-depth low-velocity zone in contrast with the more diffuse and wider low-velocity zone in the half-space cooling model.

variation to reconcile it with observations on the depth extent of seismic anisotropy below oceanic lithosphere. The calculations were done for a constant frequency of $10 \mathrm{~s}$. More recent studies predict similar attenuation sensitivity to temperature but differ in their parameterization of grain-size sensitivity [Jackson and Faul, 2010; McCarthy et al., 2011] and have not been complemented with a dehydration parameterization and a grain-size versus depth profile; hence, we use only $Q_{\mathrm{F}}$ in this study [see Goes et al., 2012 for more discussion of the sensitivity to Q models].

[20] Calculated shear-velocity structures for the half-space and plate cooling models are shown in Figure 8. The compressional-velocity structure has similar characteristics. Velocities in the upper $6.5 \mathrm{~km}$ are taken from profile A0 for the oceanic crust from the CRUST2.0 model [Bassin et al., 2000]. Due to the limitation on plate thickness, the upper mantle in the plate model has a relatively narrow low-velocity asthenosphere where $S$ velocities $<4.3 \mathrm{~km} / \mathrm{s}$ are confined to a depth range of $100-140 \mathrm{~km}$. The strength and depth of the low-velocity zone do not vary with plate age. In contrast, the low-velocity zone in the half-space cooling model varies in both depth and amplitude with age from a minimum $\mathrm{V}_{S}$ of $4.26 \mathrm{~km} / \mathrm{s}$ at $104-\mathrm{km}$ depth at $50 \mathrm{Myr}$ to a minimum $\mathrm{V}_{S}$ of $4.44 \mathrm{~km} / \mathrm{s}$ at 185-km depth at 200 Myr. The low-velocity zone in a model where plate thickness is limited by small-scale convection is intermediate in thickness and depth increases with age between the half-space and plate models [Ritzwoller et al., 2004].

[21] The dehydration effects as included in our modeling have been proposed as a possible cause of the enigmatic "LAB" velocity discontinuity [Karato, 2012; Karato and Jung, 1998]. Indeed, Figure 8 displays a relatively sharp velocity gradient near the depth where dry melting starts, in young lithosphere ( $<30 \mathrm{Myr})$. If dehydration progresses more nonlinearly with depth, sharper gradients that persist to ages as high as 80-90 Myr can be generated. Other mechanisms that have been proposed to contribute to the "LAB" velocity discontinuity are a change in anelastic deformation mechanism [Karato, 2012], presence of anisotropy [Rychert et al., 2012], and a layer of pooled melt [Kawakatsu et al., 2009]. Our models do not predict the first effect when using the attenuation parameters for different mechanisms as given in Jackson and Faul [2010], whereas anisotropy and melt may vary regionally and contribute to deviations from age-dependent structure.

[22] The seismic velocity structures in the synthetic models are lower than in IASP91 (and other global reference models) above the 400-km discontinuity [e.g., Cammarano et al., 2003, 2005] (Figure 9). The wave speeds in IASP91 are biased high because traveltime data originate primarily from stations on land and earthquakes near subduction zones. The traveltime calculations require a velocity profile for the entire mantle. Global and regional tomographic models show that, at 250- to $300-\mathrm{km}$ depth, the correlation of velocity structure with surface tectonics and the continentocean distribution disappears [e.g., Priestley and McKenzie, 2006; Ritsema et al., 2004; Röhm et al., 2000]. Because our focus is on modeling oceanic lithosphere-asthenosphere structure, we merge the velocities of our cooling models
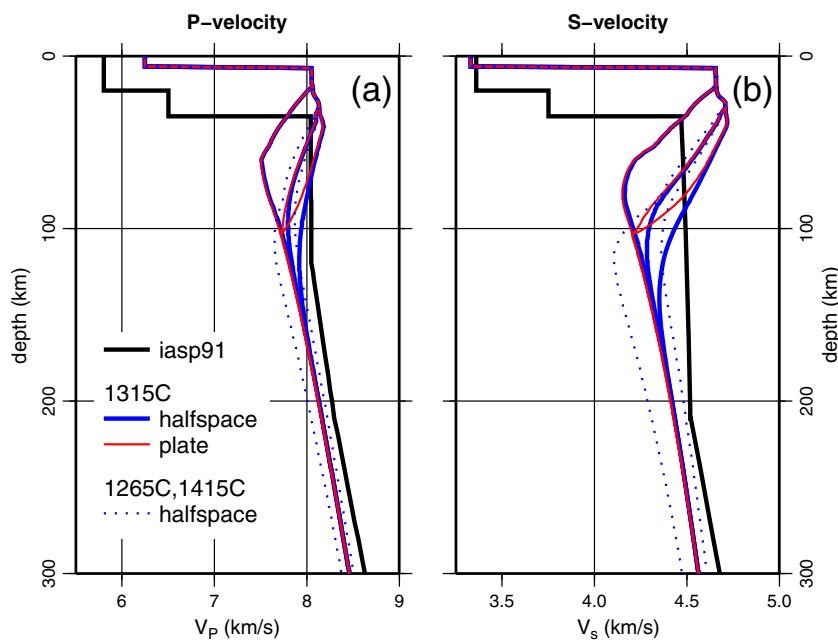

Figure 9. Synthetic $P$ and $S$ velocities for the half-space (blue) and plate cooling (red) models from Figure 7 (potential mantle temperature of $1315^{\circ} \mathrm{C}$ ) are compared along profiles for ages of 20,60, and $100 \mathrm{Myr}$ (solid lines) and slower than IASP91 (bold black line) down to 400-km depth. Sensitivity to temperature is illustrated by half-space cooling profiles (blue, dotted lines) for 60-Myr-old lithosphere for potential mantle temperatures of $1265^{\circ} \mathrm{C}$ (faster velocities) and $1415^{\circ} \mathrm{C}$ (slower). 

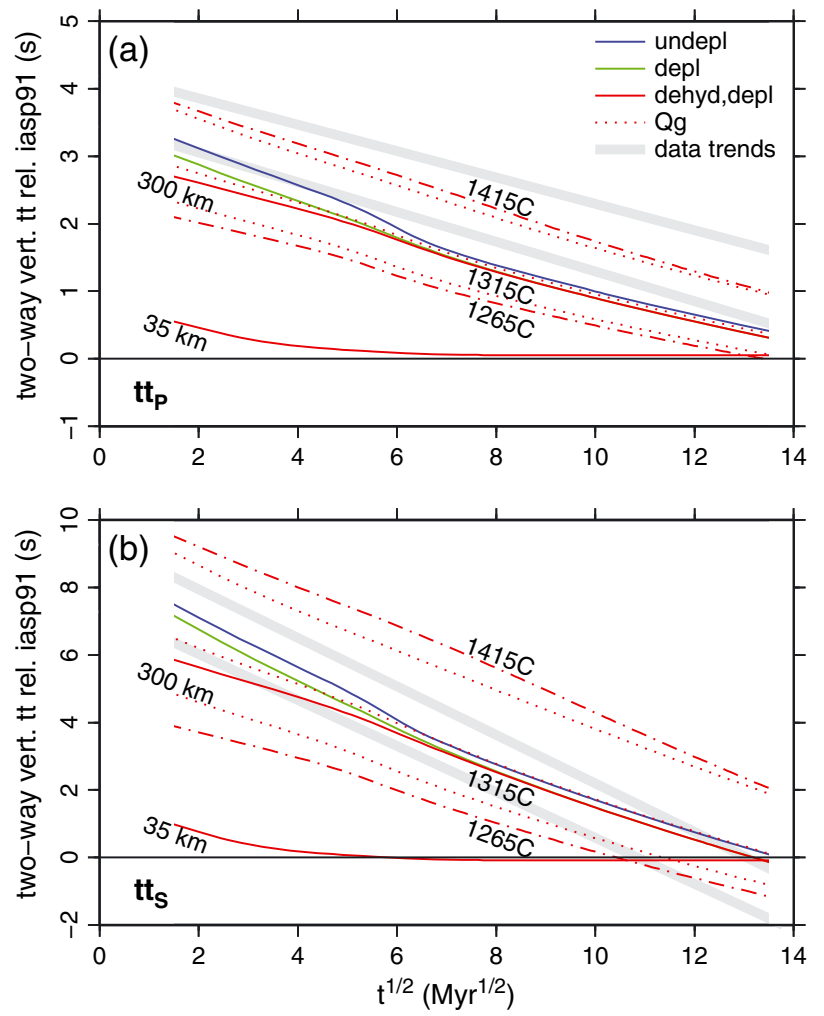

Figure 10. 1-D vertical two-way $P$-wave (a) and $S$-wave (b) traveltimes versus $t^{1 / 2}$, integrated from $300-\mathrm{km}$ depth to the surface. Traveltimes are shown as the difference from IASP91 with a CRUST2.0 standard A0 oceanic crust and mantle structure down to 35-km depth (base of the IASP91 crust). Data trends shown for comparison are from the fits to the mean Pacific and other-ocean traveltimes (Figure 6), which are for a range of incidence angles (generally $<30^{\circ}$ ). The vertical traveltime synthetics provide a minimum path length and hence lower bound traveltime estimate. Solid lines are synthetic times calculated for the half-space cooling model with potential temperature of $1315^{\circ} \mathrm{C}$ (Figure 7), with anelasticity model $Q_{\mathrm{F}}$ (Figure 8). The curve labeled $35 \mathrm{~km}$ is the traveltime difference integrated to $35-\mathrm{km}$ depth only, illustrating the contribution from the crust and subcrustal mantle to the anomalies. (blue and green curves) Illustrate the small effect that major-element depletion and dehydration have on the traveltimes. (dasheddotted curves) Traveltimes for a half-space model with a $50^{\circ}$ cooler potential mantle temperature $(1265 \mathrm{C})$ and $100^{\circ}$ warmer mantle temperature $(1415 \mathrm{C})$. The dotted lines for the three potential temperatures are traveltimes calculated with an alternative anelasticity model (model $Q_{\mathrm{g}}$ ) [Goes et al., 2012].

with the IASP91 profile over the depth interval between $200-$ and $250-\mathrm{km}$ depth or between $300-$ and $350-\mathrm{km}$ depth.

\subsection{Synthetic Traveltimes}

[23] We calculate $S S-S$ and $P P-P$ traveltimes using the TauP method [Crotwell et al., 1999] for 1-D velocity profiles appropriate for the plate age at the bounce point. The traveltimes were calculated for the same source depth and epicentral distance combinations as in the actual data set. A crustal correction was applied for the A0 profile of CRUST2.0, representative of the oceanic crust [Bassin et al., 2000] down to the base of IASP91 crust at $35-\mathrm{km}$ depth, similar to the crustal corrections applied to the data.

\section{Results}

\subsection{Vertical Traveltimes and Parameter Sensitivity}

[24] To illustrate the effect of the crustal correction, the assumed major-element and water depletion, and the choice of potential mantle temperature, we compare the two-way vertical traveltimes through the structures as a function of age. The results for $P$ and $S$ wave propagation through the half-space cooling model are shown in Figure 10.

[25] The crustal corrections increase the traveltime anomalies because the mantle velocities in the A0 model are higher than the mantle velocities in our thermal structures. Below $35-\mathrm{km}$ depth, the mantle velocities are lower than in IASP91; hence, $P P-P$ and $S S-S$ anomalies are positive and decrease with increasing plate age. If we shift the merging depth between our cooling structures and IASP91 from 300- to 200-km depth, the $P$ traveltime differences decrease by about half a second (see section 4.2). For $S$ waves, the anomalies are about a factor of 2 higher, and the trends with age are steeper.

[26] Both dehydration and major-element depletion reduce the $P P-P$ and $S S-S$ anomalies by $<0.6 \mathrm{~s}$ in $P$ and $<1.5 \mathrm{~s}$ in $S$ and only for the lowest $(<30 \mathrm{Myr})$ ages. This is a small amount given the large scatter in the actual traveltime data. If a narrower dehydration interval is assumed, over a $5-\mathrm{km}$ depth interval below the depth where dry melting starts, estimated traveltimes of two-way vertical $P$ and $S$ traveltimes slightly increase by $\leq 0.1$ and $\leq 0.3 \mathrm{~s}$, respectively.

[27] The effect of potential temperature is significant. We modeled velocities for a $50^{\circ}$ cooler and $100^{\circ}$ hotter potential mantle temperature. Depletion and dehydration depths as well as adiabatic gradients were shifted to match those of corresponding dynamic spreading models and thermodynamically predicted adiabats. A $50^{\circ}$ cooler mantle results in anomalies that are $0.3-0.6 \mathrm{~s}$ lower for $P$ over the full age range and $0.9-1.9$ s lower for $S$, whereas a $100^{\circ}$ hotter mantle predicts larger traveltime anomalies by $0.6-1.1 \mathrm{~s}$ for $P$ and $2.0-3.6 \mathrm{~s}$ for $S$. Traveltimes calculated for the three potential-temperature models with an alternative anelasticity model, model $Q_{\mathrm{g}}$ [Goes et al., 2012], which has a different temperature and pressure dependence than $Q_{\mathrm{F}}$, span a somewhat smaller range, between 0.1 and $0.9 \mathrm{~s}$ less than those with model $Q_{\mathrm{F}}$.

[28] For comparison, Pacific and other ocean trends are plotted in the background. Synthetic trends are similar to the observed ones, and the difference between Pacific and other oceans is of a similar magnitude as that expected for a difference in $50-100^{\circ} \mathrm{C}$ potential temperature. Do note that the data trends are not corrected to vertical traveltimes. However, when ray geometry is accounted for, model and data trends are also similar, as shown in the next section.

\subsection{Trends With Age}

[29] Figure 11 compares the synthetic $P P-P$ and $S S-S$ traveltime anomalies for the same distribution of epicentral distances and source depths as in the data. All synthetic traveltimes cluster tightly around the age trend within $\pm 0.3 \mathrm{~s}$ for $P P-P$ and $\pm 0.5 \mathrm{~s}$ for $S S-S$. Traveltimes for the plate and half-space cooling model are only slightly different, relative to the large scatter in the data. The half-space model predicts a constant $t^{1 / 2}$ decrease in $P P-P$ and $S S-S$ times, whereas, for 

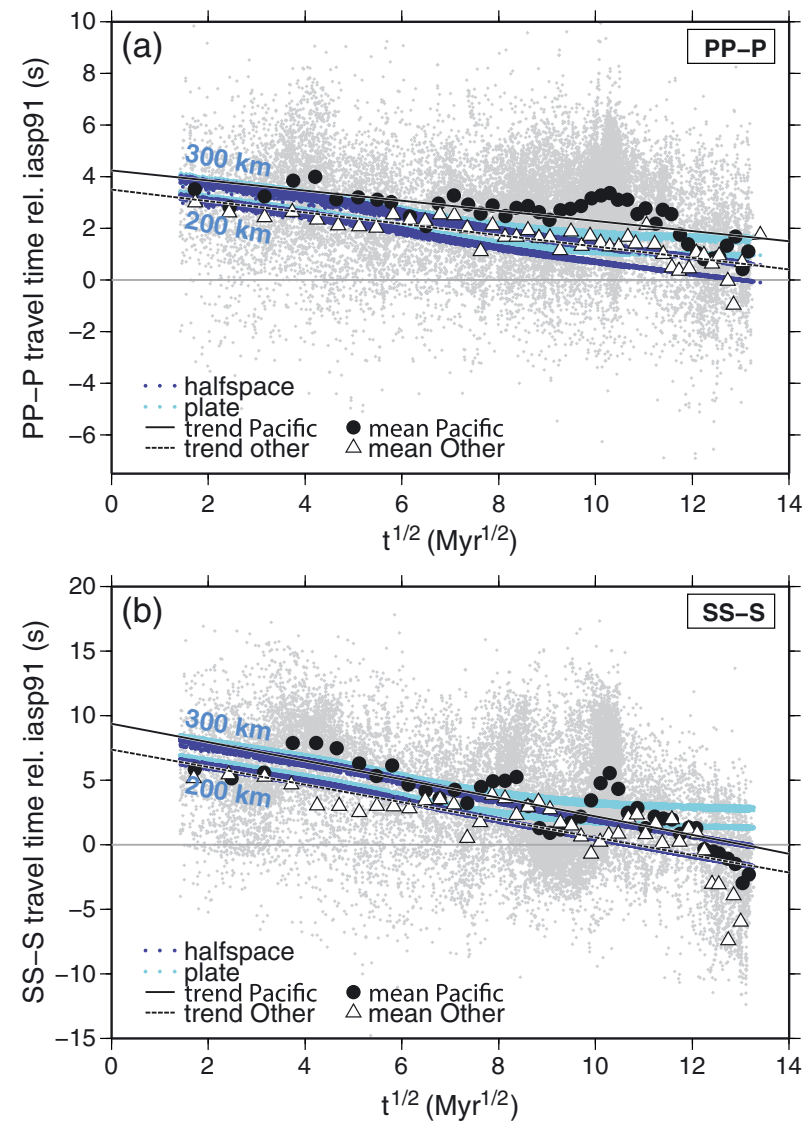

Figure 11. $P P-P($ a) and $S S-S$ (b) traveltimes calculated through half-space (blue dots) and plate (cyan dots) models in Figures 7 and 8 for the same depth-epicentral distance distribution as the actual data (gray dots). The different path geometries only result in a narrow range of times for each age. Two model trends are plotted for each cooling model, for oceanic velocity structures merging with IASP91 below 200 and $300 \mathrm{~km}$. Mean Pacific and other-ocean values and trends from Figure 6 are shown in black symbols and lines. The first-order data trend and average values of both $P$ and $S$ differential traveltimes are similar to that of the cooling models.

the plate model, the rate of decrease levels off for ages larger than $80 \mathrm{Myr}$ when the lithosphere no longer thickens.

[30] The decrease of the synthetic PP-P times with $t^{1 / 2}$ is $0.29 \mathrm{~s} / \mathrm{Myr}^{1 / 2}$ for the half-space model and $0.22 \mathrm{~s} / \mathrm{Myr}^{1 / 2}$ for the plate model. Synthetic SS-S times decrease by $0.73 \mathrm{~s} / \mathrm{Myr}^{1 / 2}$ for the half-space and $0.52 \mathrm{~s} / \mathrm{Myr}^{1 / 2}$ for the plate model. The $P$ trend is matched better by the plate-model trend, whereas the $S$ trend is explained better by the halfspace cooling model. However, the difference in fit of the two models to the actual distribution of mean values with age is not significant. That is, we cannot distinguish between the two end-members with this data set. We do point out, however, that neither the $P P-P$ nor the $S S-S$ anomalies from the Pacific and Atlantic oceans display the systematic change in age trend for lithosphere older than 70-80 Myr that would be expected for age-dependent reheating. Rather, the scatter in the data is significant and there are regional effects (discussed in section 4.3).
[31] Figure 11 demonstrates that, to a first order, the average oceanic $P P-P$ and $S S-S$ traveltimes can be reconciled with the lithosphere-asthenosphere structure expected from age-dependent lithospheric cooling above a mantle with a MORB-source compatible potential temperature of $1315^{\circ} \mathrm{C}$. Uncertainties in absolute temperatures from seismic velocities at lithospheric depths are $\pm 50 \mathrm{~K}$ [Cammarano et al., 2003]; uncertainties in inferred temperature anomalies are smaller. The difference between the Pacific $P P-P$ and $S S-S$ data and those for other oceans could be explained by $50-100^{\circ}$ variation in the average mantle temperature beneath the different oceans. Such temperature differences would need to be sustained by mantle flow, such as large-scale variations in plume flux.

\subsection{Deviations From Lithospheric Cooling}

[32] In Figure 12, we show $P P-P$ and $S S-S$ referenced to model HS200, the half-space cooling model that extends to $200-\mathrm{km}$ depth. HS200 provides a reasonable match to both $P P-P$ and $S S-S$ for the oceans other than the Pacific (the Pacific contains a number of highly sampled very slow paths; Figures 11 and 12). The residual traveltimes are almost the same with the plate model as a reference. The sign and distribution of $P P-P$ and $S S-S$ anomalies are similar and reveal the oceanic regions that cannot be explained by cooling models. Positive and negative residuals imply that the seismic velocities are lower and higher than expected for the cooling models.

[33] The distribution of the residuals is determined by coverage. For example, the NW-SE trending cluster of bounce points in the central Pacific anomaly is the result of abundant Tonga-North America source-receiver paths. These paths are also responsible for the high number of measurements in the age range of 80-130 Myr shown in Figure 6. Some of the residuals may be affected by anisotropy, because coverage of specific regions is often dominated by a limited set of sourcereceiver paths. On the contrary, the very broad scale of the main anomalies that emerge and consistency between $P$ and $S$ patterns indicate that this is likely not the dominant effect.

[34] The residuals in the central-northern Pacific stand out. They indicate that the seismic velocities there are anomalously low. There are some differences between the $P P-P$ (slow) and SS-S (fast) traveltime residuals near Hawaii. The traveltime residuals for the Philippine Sea region are negative, indicating that the upper-mantle velocities are anomalously high. The residuals in the southern Pacific are positive but, like the residuals in the Indian and Atlantic oceans, are generally smaller than in the northern Pacific. Because data coverage in the Indian Ocean is relatively poor, few patterns emerge, except that the anomalies appear somewhat faster in the Southern Ocean between Australia and Antarctica than in the Indian Ocean. The residuals in the South Atlantic are negative (i.e., fast) and they are more mixed in the northern Atlantic, indicating that it has more slow anomalies than the South Atlantic.

[35] To better understand the patterns in Figure 11, we analyzed the traveltime residuals for common source-receiver combinations. A summary for the most prominent anomalies is shown in Figure 13. For example, the $P P$ and $S S$ bounce points for the Tonga-to-Western U.S. paths are in the central Pacific (region 3), whereas the bounce points for Central America-to-Europe paths are in the Northern Atlantic (region 6). In addition to differential traveltimes, we analyze the residuals of the direct $(P$ or $S)$ and reflected $(P P$ or $S S$ ) waves. 

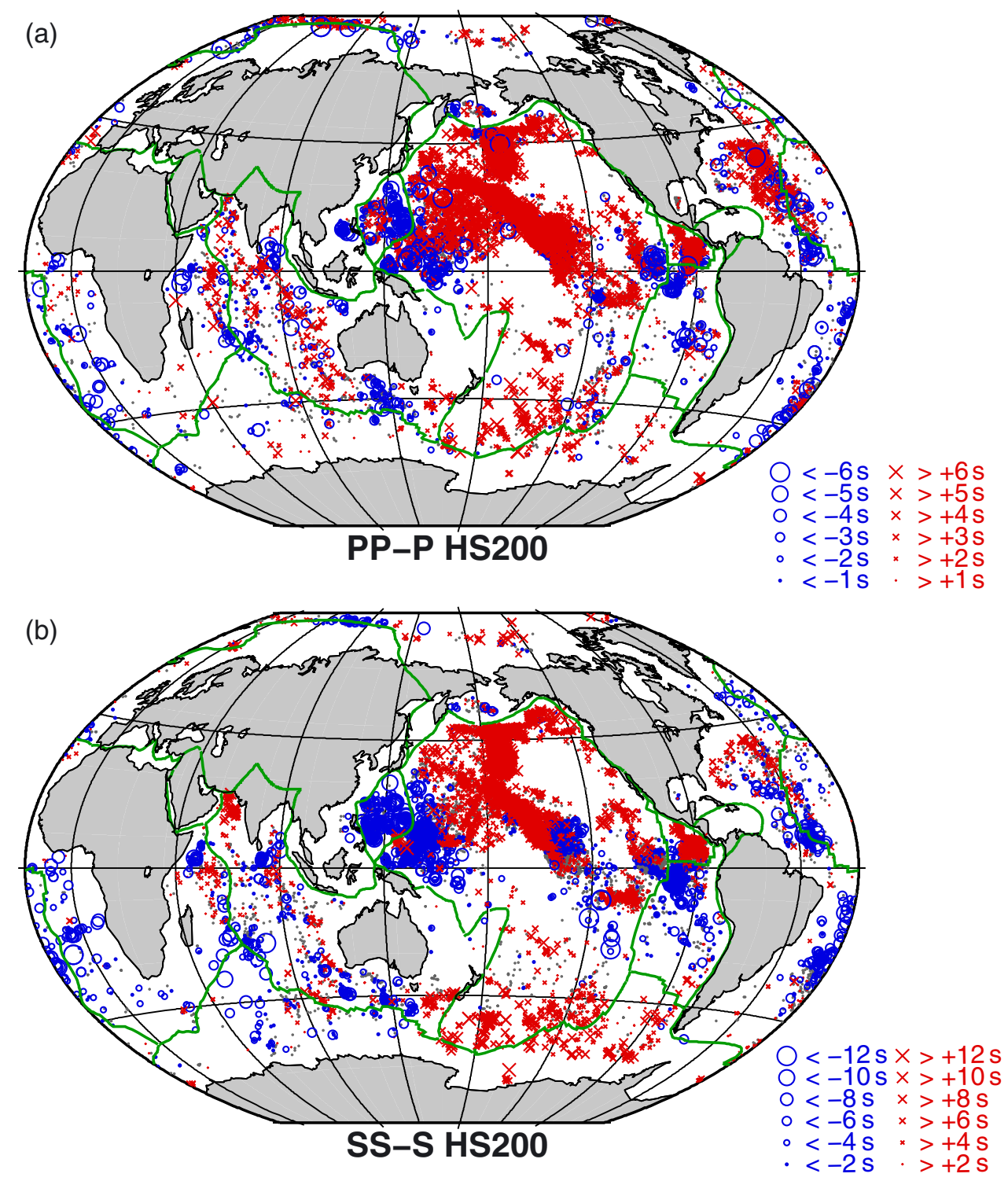

Figure 12. Maps of oceanic differential $P P-P$ (a) and $S S-S$ (b) traveltime anomalies relative to a halfspace cooling model with potential $\mathrm{T}$ of $1315^{\circ} \mathrm{C}$ that from $200-\mathrm{km}$ depth grades into IASP91. Large-scale patterns that are similar in $P$ and $S$ data emerge. They illustrate significant shallow mantle lateral structure below the oceans, including anomalously slow upper mantle in the northern-central Pacific.

The path-set histograms are relatively simple with single peaks, sometimes with skew. We find that the mean values, which are shown in Figure 12, sufficiently characterize the distributions to provide insight in the observed patterns.

[36] We mostly find the same influence of source and receiver structure on the traveltimes of the direct $(P$ and $S$ ) and reflected $(P P$ and $S S$ ) waves. Data subsets 4 and 7 (for sources along the South American subduction zone), subset 6 (for sources in Central America), and subset 8 and 9 (for sources in southeast Asia) indicate that the high velocities within the subduction zones produce the negative traveltime delays of the direct and reflected waves. However, the differential traveltimes reveal a difference between North Atlantic and South Atlantic and that the average Indian Ocean is slower than both the South Atlantic and the Southern Ocean.
[37] The Pacific data of subset 2 are associated with sources along the western Pacific subduction zones and receivers in the Western United States. The traveltime residuals of $P$ and $S$ are negative presumably due to high velocities in the subduction zone. However, the $P P$ and $S S$ residuals are positive and likely dominated by low velocities in the upper mantle below the bounce points in the northern-central Pacific.

[38] In the central Pacific (subset 3), the positive residuals of the reflected waves are similar to those from subset 2 in the northern Pacific. However, the residuals of $P$ and $S$ appear to be substantially influenced by the large-low shear-velocity province (LLSVP) in the lower mantle below the Pacific. This structure is known to influence $S$ waves more than $P$ [e.g., Ritsema and Van Heijst, 2002; Takei, 2002]. In our data, the $S$ residuals (with respect to HS200) are $+4 \mathrm{~s}$, whereas the 


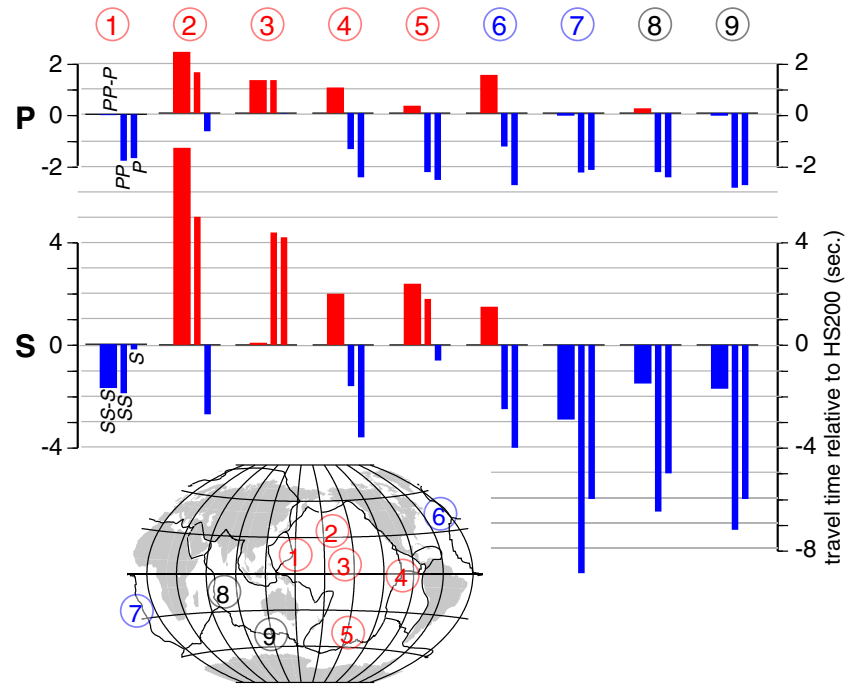

Figure 13. Mean traveltimes relative to HS200 (half-space cooling model with potential temperature of $1315^{\circ} \mathrm{C}$ that merges with IASP91 below 200-km depth) for selected paths with similar bounce point regions. (bold bars) Differential $P P-P$ (top) and $S S-S$ (bottom) times. (thin bars) Traveltimes of $P P$ and $P$ (top) and $S S$ and $S$ (bottom) for comparison. (blue bars) Times that are fast relative to HS200. (red bars) Times that are slow. The bounce-point regions are marked on the inset: red for Pacific Ocean, blue for Atlantic Ocean, and black for Indian Ocean. Note that the regions vary in size and number of rays included (up to 3000 for region 3 and as low as 100 for region 9), and there are different numbers of rays for $P$ and $S$ data. Paths for the regions are from (1) Vanuatu-New Guinea to East Asia, (2) West Pacific to Western United States, (3) Tonga to Western United States, (4) South America to Western United States, (5) Tonga to South America, (6) Central America to Europe, (7) South America to Africa, (8) Southeast Asia to Africa, and (9) Southeast Asia to Antarctica.

$P$ residuals are almost zero. The difference in the $P$ and $S$ residuals renders the different $P P-P$ and $S S-S$ patterns near Hawaii (Figure 11). Here, the negative $S S-S$ residuals are primarily a result of delayed $S$ wave propagation through the LLSVP rather than high velocities in the upper mantle.

[39] The western Pacific data of subset 1 appear to be influenced by the LLSVP as well. In this case, $P P-P$ is about zero as the residuals of both $P P$ and $P$ are negative presumably due to the high velocities in the Tonga subduction zone and beneath the stations in Asia. On the contrary, SS-S residuals are negative because the LLSVP delays the $S$ wave, but it affects $P$ much less.

[40] The dense sampling of the slow central Pacific and the effect of the LLSVP can explain the difference in shape between the oceanic PP-P and SS-S histograms in Figure 3 and their similar mean values. The LLSVP effect is likely also responsible for the slight negative correlation between $S$ and $S S-S$ traveltimes shown in Figure 4. Our analyses show that these biases are not characteristic of all oceans, and most of the differential traveltimes can be understood as a signature of shallow mantle thermal structure.

[41] The positive $S S-S$ and $P P-P$ residuals in the central and northern Pacific coincide with a much broader region that Ritzwoller et al. [2004] previously identified using surfacewave tomography as having a lower velocity than expected from half-space cooling. Our study shows that this region is anomalous compared with other oceanic regions. If these low velocities in the upper mantle are due to lithospheric thinning by small-scale convection as suggested by Ritzwoller et al. [2004], the onset of such destabilization cannot purely be a function of age. As Hawaii is located in the middle of this region, a relation to plume activity presents itself.

[42] Interestingly, the residual anomalies near the midocean ridges reflect patterns in ridge bathymetry. For example, the south Atlantic Ridge, where residual times relative to the cooling model are negative, is less elevated than the ridge in the North Atlantic [e.g., Zhang et al., 1994]. Similarly, the Pacific-Antarctic ridge, where there is a concentration of positive residuals, is consistently shallower [Buck et al., 2009] than the East-Pacific Rise and the Australia-Antarctic Ridge, where residuals are (more) negative. Also, the ridge south of Australia has a well-known minimum in bathymetry, the AustralianAntarctica Discordance, and is underlain by a negative $P P-P$ and $S S-S$ residuals. These anomalies may correspond to variations in asthenospheric temperature, or asthenospheric thickness as preferred by Buck et al. [2009], and may relate to plume flux (e.g., in the southern Pacific and northern Atlantic).

\section{Conclusions}

[43] We analyzed $\sim 60,000$ differential $P P-P$ and $S S-S$ traveltimes that provide constraints on the compressional- and shear-velocity structure in the oceanic upper mantle below the bounce points of the reflected waves. The traveltime anomalies decrease with lithospheric age. The age trends of $P P-P$ and $S S-S$ and their average positive (i.e., slow) deviations from global reference models (like IASP91) can be explained by lithospheric cooling models. This confirms that the first-order signal in these $P$ and $S$ wave traveltime data has a shallow mantle origin and is thermal in nature.

[44] The differences between synthetic traveltimes generated for two end-member cooling models, a maximum-lithosphericthickness half-space cooling model and minimum-thickness plate cooling model, are smaller than the scatter in the seismic data. Therefore, we cannot conclusively distinguish between these two end-member cooling models. On the contrary, the data show no evidence of an age-dependent limiting factor on lithospheric thickness but rather indicate significant nonage-correlated structure.

[45] There is $\pm 3 \mathrm{~s}$ of scatter in $P P-P$ and $\pm 6 \mathrm{~s}$ in $S S-S$ around a cooling trend. Residual $P P-P$ and $S S-S$ traveltimes relative to the matching half-space cooling model reveal large-scale regions of the upper mantle where compressional and shear velocities are higher or lower than expected for conductive cooling. The patterns are similar in sign and distribution for $P P-P$ and $S S-S$, except for the central and western Pacific. Here, $S S-S$ anomalies are significantly more negative than $P P-P$ anomalies. In these regions, the differential traveltimes are influenced by a low-velocity anomaly in the lower mantle beneath the Pacific. This anomaly, termed the Pacific LLSVP, retards $S$ wave propagation but has a relatively minor influence on $P$ waves. The large number of data that cross this region (Tonga-North America source-receiver pairs) results in biases in the statistics of the overall data set.

[46] Most of the differential traveltime anomalies relative to the cooling trend appear to reflect non-age-related lateral variability of shallow mantle structure. Most prominent are 
the very strong positive anomalies in the northern and central Pacific, indicating an anomalously warm mantle (by $\sim 100^{\circ} \mathrm{C}$ ) below that part of the Pacific plate. Other patterns in residual anomalies along the Atlantic, Indian, and Pacific ridges correlate with ridge bathymetry, indicating variations in thermal structure at asthenospheric depths.

\section{Appendix A: Time-Travel Age Trends}

[47] Differential $P P-P$ and $S S-S$ travel times for waves with oceanic bounce points display a trend with plate age that we interpret as a signature of lithospheric cooling. The figures below support the interpretation of this age dependence as a shallow-mantle signature. The age trend is present in the
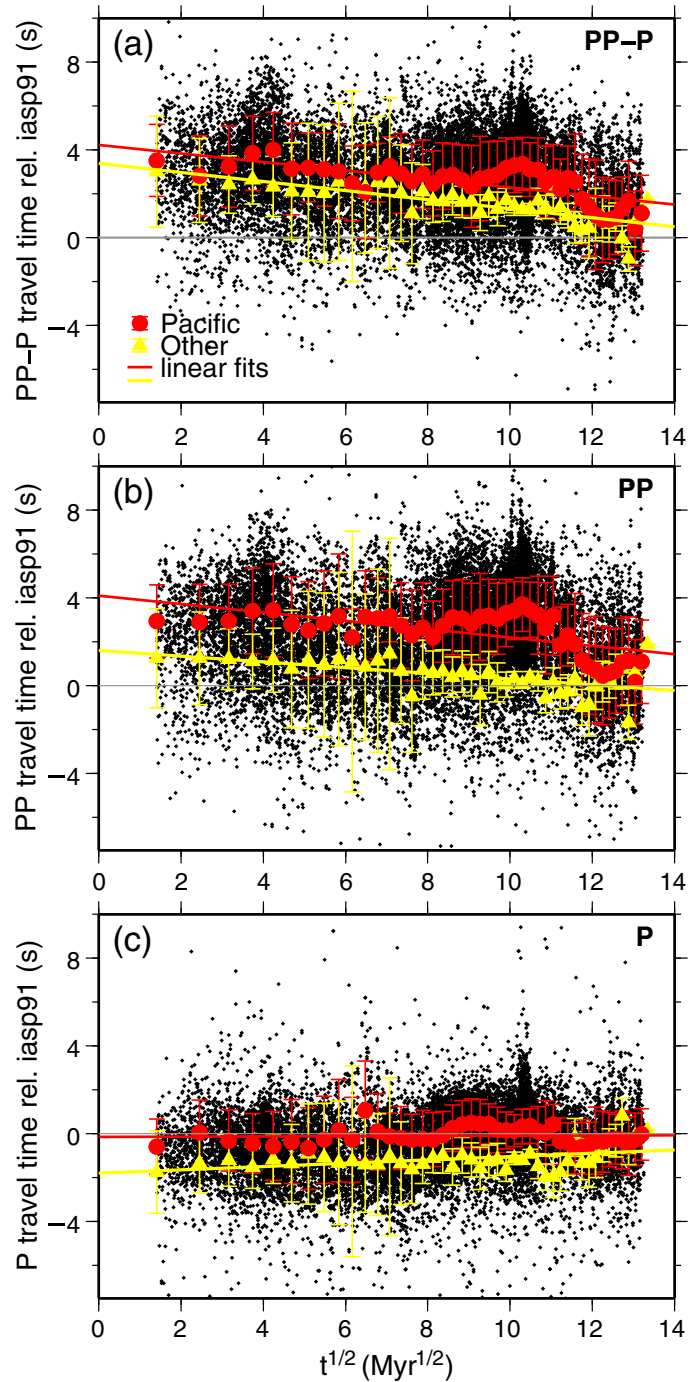

Figure A1. Differential $P P-P(\mathrm{a}), P P(\mathrm{~b})$ and $P$ (c) traveltimes relative to IASP91, as a function of the square root of plate age, $\mathrm{t}^{1} / 2$. Black dots display the full data set, red symbols the mean traveltimes with standard deviations for the Pacific data, yellow symbols the mean data plus standard deviations for all other oceans. Lines are linear least-square fits to the means. $P P-P$ data display the clearest age trend, while there is a less clean age trend in the $P P$ data and no clear trend in $P$.
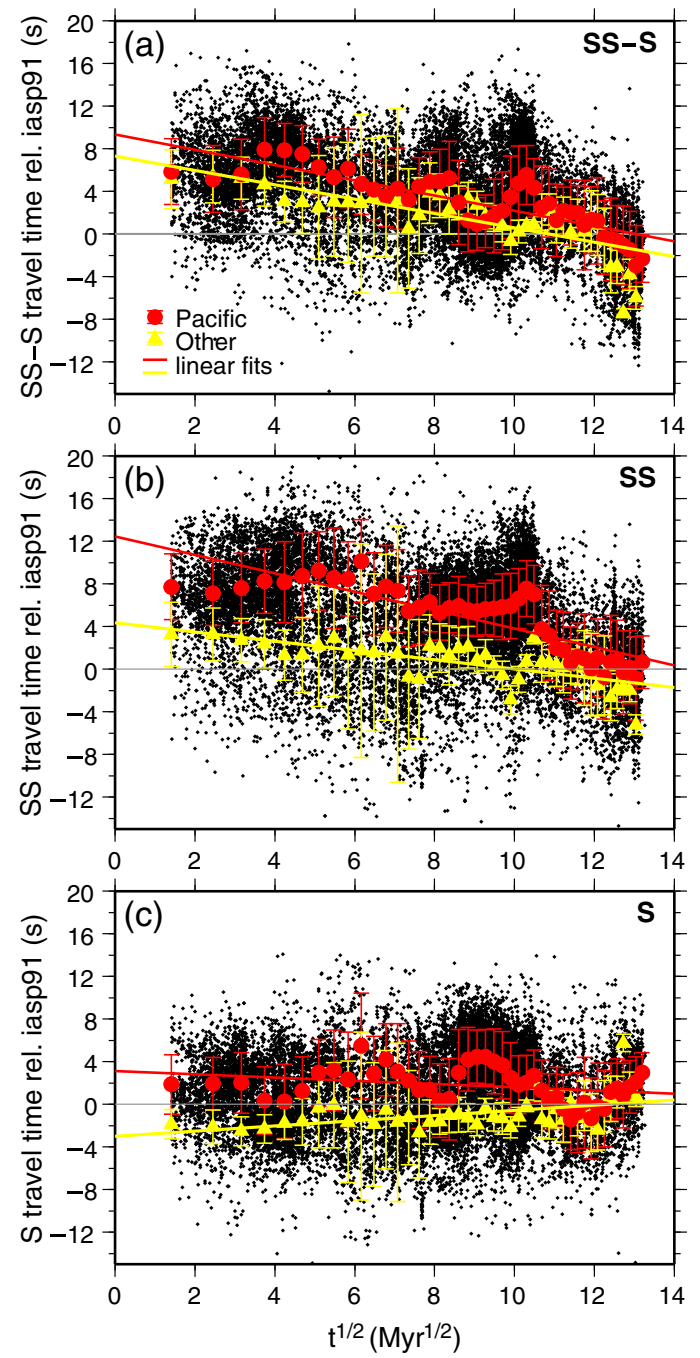

Figure A2. Differential $S S-S$ (a), $S S$ (b) and $S$ (c) traveltimes relative to IASP91, as a function of the square root of plate age, $\mathrm{t}^{1} \frac{1}{2}$. Black dots display the full data set, red symbols the mean traveltimes with standard deviations for the Pacific data, yellow symbols the mean data for all other oceans. Lines are linear least-square fits to the means. Traveltime scale is twice that of Figure A1. As for the $P$ data in Figure A2, the $S S-S$ data display the clearest age trend.

travel times of the reflected $P P$ and $S S$ phases, for which a substantial part of their paths lies in the upper mantle, but not in the direct $P$ and $S$ travel times, which dominantly sample lower-mantle structure (Figure A1). Differencing reflected and direct travel times removes near-source and near-receiver effects and clarifies the age trend.

[48] Acknowledgments. We thank the two anonymous reviewers and the associate editor for their detailed and constructive comments that help us clarify the article. All figures were made with Generic Mapping Tools [Wessel and Smith, 1998]. The seismic data have been provided by IRIS. S.G. had support from Natural Environment Research Council standard grant NE/G004749/1, and J.R. is supported by National Science Foundation grant EAR-1014749.

\section{References}

Bassin, C., G. Laske, and G. Masters (2000), The current limits of resolution for surface wave tomography in North America, EOS Trans. Amer. Geophys. Un., 81, F897. 
Behn, M. D., G. Hirth, and J. R. Elsenbeck II (2009), Implications of grain size evolution on the seismic structure of the oceanic upper mantle, Earth Planet. Sci. Lett., 282, 178-189.

Bhattacharyya, J., G. Masters, and P. Shearer (1996), Global lateral variations of shear wave attenuation in the upper mantle, J. Geophys. Res., $101,22,273-22,289$

Buck, W. R., C. Small, and W. B. F. Ryan (2009), Constraints on asthenospheric flow from the depths of oceanic spreading centers: The East Pacific Rise and the Australian-Antarctic Discordance, Geochem. Geophys. Geosys., 10, Q09007, doi:10.1029/02009GC002373.

Cammarano, F., S. Goes, P. Vacher, and D. Giardini (2003), Inferring upper mantle temperatures from seismic velocities, Phys. Earth Planet. Int., $138,197-222$

Cammarano, F., A. Deuss, S. Goes, and D. Giardini (2005), Onedimensional physical reference models for the upper mantle and transition zone: combining seismic and mineral physics constraints, J. Geophys. Res., 110(B1), B01306 doi:10.1029/02004JB003272.

Connolly, J. A. D. (2005), Computation of phase equilibria by linear programming: a tool for geodynamic modeling and its applicationto subduction zone decarbonation, Earth Planet. Sci. Lett., 236, 524-541.

Crotwell, H. P., T. J. Owens, and J. Ritsema (1999), The TauP ToolKit: Flexible Seismic Travel-Time and Raypath Utilities, Seismol. Res. Lett., $70,154-160$.

Davaille, A., and C. Jaupart (1994), Onset of thermal convection in fluids with temperature-dependent viscosity: Application to the oceanic mantle, J. Geophys. Res., 99(B10), 19,853-866.

Doin, M. P., and L. Fleitout (1996), Thermal evolution of the oceanic lithosphere: an alternative view, Earth Planet. Sci. Lett., 142, 121-136.

Faul, U. H., and I. Jackson (2005), The seismological signature of temperature and grain size variations in the upper mantle, Earth Planet. Sci. Lett., 234(1-2), 119-134.

Goes, S., J. Armitage, N. Harmon, H. Smith, and R. Huismans (2012), Low seismic velocities below mid-ocean ridges: Attenuation versus melt retention, J. Geophys. Res., 117, B12403, doi:10.1029/2012JB009637.

Harmon, N., D. W. Forsyth, D. S. Weeraratne, Y. Yang, and S. C. Webb (2011), Mantle heterogeneity and off axis volcanism on young Pacific lithosphere, Earth Planet Sci. Lett., 311, 306-315.

Herzberg, C., P. D. Asimow, N. Arndt, Y. Niu, C. M. Lesher, J. G. Fitton, M. J. Cheadle, and A. D. Saunders (2007), Temperatures in ambient mantle and plumes: Constraints from basalts, picrites, and komatiites, Geochem. Geophys. Geosyst., 8(2), Q02006.

Hillier, J. K., and A. B. Watts (2005), Relationship between depth and age in the North Pacific Ocean, J. Geophys. Res., 110, B02405.

Hirth, G., and D. L. Kohlstedt (1996), Water in the oceanic upper mantle: Implications for rheology, melt extraction and the evolution of the lithosphere, Earth Planet. Sci. Lett., 144, 93-108.

Hofmeister, A. (1999), Mantle values of thermal conductivity geotherm from phonon lifetimes, Science, 283, 1699-1709.

Huang, J., and S.-J. Zhong (2005), Sublithospheric small-scale convection and its implications for residual topography at old ocean basins and the plate model, J. Geophys. Res., 110, B05404. doi:10.1029/ 02004JB003153.

Jackson, I., and U. H. Faul (2010), Grainsize-sensitive viscoelastic relaxation in olivine: Towards a robust laboratory-based model for seismological application, Phys. Earth Planet. Int., 183, 151-163.

Jackson, I., J. D. Fitz Gerald, U. H. Faul, and B. H. Tan (2002), Grain-sizesensitive seismic wave attenuation in polycrystalline olivine, J. Geophys. Res., 107(B12), 2360, doi:10.1029/2001JB001225.

Karato, S. (1993), Importance of anelasticity in the interpretation of seismic tomography, Geophys. Res. Lett., 20, 1623-1626.

Karato, S., and H. A. Spetzler (1990), Defect microdynamics in minerals and solid-state mechanisms of seismic wave attenuation and velocity dispersion in the mantle, Rev. Geophys., 28, 399-421.

Karato, S.-I. (2012), On the origin of the asthenosphere, Earth Planet Sci. Lett., 321-322, 95-103.

Karato, S.-i., and H. Jung (1998), Water, partial melting and the origin of the seismic low velocity and high attenuation zone in the upper mantle, Earth Planet. Sci. Lett., 157(3-4), 193-207.

Kawakatsu, H., P. Kumar, Y. Takei, M. Shinohara, T. Kanazawa, E. Araki, and K. Suyehiro (2009), Seismic evidence for sharp lithosphereasthenosphere boundaries of oceanic plates, Science, 324, 499-502.

Kennett, B. L. N., and E. R. Engdahl (1991), Traveltimes for global earthquake location and phase identification, Geophys. J. Int., 105, 429-465.
Korenaga, T., and J. Korenaga (2008), Subsidence of normal oceanic lithosphere, apparent thermal expansivity, and seafloor flattening, Earth Planet. Sci. Lett., 268, 41-51.

Maggi, A., E. Debayle, K. Priestley, and G. Barruol (2006), Multimode surface waveform tomography of the Pacific Ocean: a closer look at the lithospheric cooling signature, Geophys. J. Int., 166, 1384-1397, doi: 10.1111/j.1365-1246X.2006.03037.x.

McCarthy, C., Y. Takei, and T. Hiraga (2011), Experimental study of attenuation and dispersion over a broad frequency range: 2 . The universal scaling of polycrystalline materials, J. Geophys. Res., 116, B09207.

McKenzie, D., J. Jackson, and K. Priestley (2005), Thermal structure of oceanic and continental lithosphere, Earth Planet. Sci. Lett., 233, 337-349.

Müller, R. D., M. Sdrolias, C. Gaina, and W. R. Roest (2008), Age, spreading rates and spreading asymmetry of the world's ocean crust, Geochem Geophys. Geosys., 9, doi:10.1029/2007GC001743.

Nishimura, C., and D. W. Forsyth (1989), The anisotropic structure of the upper mantle in the Pacific, Geophys. J. Int., 96, 203-229.

Parson, B., and J. G. Sclater (1977), An analysis of the variation of ocean floor bathymetry and heat flow with age, J. Geophys. Res., 82, 803-827.

Priestley, K., and D. McKenzie (2006), The thermal structure of the lithosphere from shear wave velocities, Earth Planet. Sci. Lett., 244, 285-301.

Reid, F. J. L., J. H. Woodhouse, and H. J. van Heijst (2001), Upper mantle attenuation and velocity structure from measurements of differential S phases, Geophys. J. Int., 145, 615-630.

Ritsema, J., and H. J. Van Heijst (2002), Constraints on the correlation of P- and S-wave velocity heterogeneity in the mantle from P,PP,PPP and PKPab traveltimes, Geophys. J. Int., 149, 482-489.

Ritsema, J., H. J. van Heijst, and J. H. Woodhouse (2004), Global transition zone tomography, J. Geophys. Res., 109, doi:10.1029/2003JB002610.

Ritsema, J., H. J. van Heijst, J. H. Woodhouse, and A. Deuss (2009), Longperiod body wave traveltimes through the crust: implication for crustal corrections and seismic tomography, Geophys. J. Int., 179, 1255-1261.

Ritsema, J., L. A. Rivera, D. Komatitsch, J. Tromp, and H. J. van Heijst (2002), Effects of crust and mantle heterogeneity on PP/P and SS/S amplitude ratios, Geophys. Res. Lett., 29, doi: 10.1029/2001GL013831.

Ritzwoller, M. H., N. M. Shapiro, and S.-J. Zhong (2004), Cooling history of the Pacific lithosphere, Earth Planet. Sci. Lett., 226, 69-84.

Röhm, A. H. E., R. K. Snieder, S. Goes, and J. Trampert (2000), Thermal structure of continental upper mantle inferred from $S$ wave velocity and surface heat flow, Earth Planet Sci. Lett., 181, 395-407.

Rychert, C. A., N. Schmerr, and N. Harmon (2012), The Pacific lithosphereasthenosphere boundary: Seismic imaging and anisotropic constraints from SS waveforms, Geochem. Geophys. Geosys., 13, Q0AK10.

Shapiro, N. M., and M. H. Ritzwoller (2004a), Inferring surface heat flux distributions guided by a global seismic model: particular application to Antarctica, Earth Planet Sci. Lett., 223, 213-224.

Shapiro, N. M., and M. H. Ritzwoller (2004b), Thermodynamic constraints on seismic inversions, Geophys. J. Int., 157, 1175-1188.

Smith, W. H., and D. T. Sandwell (1997), Global sea floor topography from satellite altimetry and ship depth soundings, Science, 277, 1956-1962.

Stein, C. A., and S. Stein (1992), A model for the global variation in oceanic depth and heat flow with lithospheric age, Nature, 359, 123-130.

Stixrude, L., and C. Lithgow-Bertelloni (2005), Mineralogy and elasticity of the oceanic upper mantle: Origin of the low-velocity zone, J. Geophys. Res., 110, B03204, doi:10.1029/02004JB002965.

Takei, Y. (2002), Effect of pore geometry on VP/VS: From equilibrium geometry to crack, J. Geophys. Res., 107(B2), 2043.

Wessel, P., and W. H. F. Smith (1998), New, improved version of Generic Mapping Tools released, EOS Trans. Amer. Geophys. Un., 79 (47), 579.

Woodward, R. L., and G. Masters (1991), Global upper mantle structure from long-period differential travel times, J. Geophys. Res., 96, 6351-6377.

Xu, W., C. Lithgow-Bertelloni, L. Stixrude, and J. Ritsema (2008), The effect of bulk composition and temperature on mantle seismic structure, Earth Planet. Sci. Lett, 275, 70-79.

Zhang, Y.-S., T. Tanimoto, and E. Stolper (1994), S-wave velocity, basalt chemistry and bathymetry along the Mid-Atlantic Ridge, Phys. Earth Planet. Int., 84, 79-93.

Zlotnik, S., J. C. Afonso, P. Díez, and M. Fernández (2008), Small-scale gravitational instabilities under the oceans: Implications for the evolution of oceanic lithosphere and its expression in geophysical observables, Phil. Mag., 88, 28, 3197-3217. 